\title{
Teoria social da retórica
}

\section{João Hilton Sayeg-Siqueira ${ }^{1}$}

uintiliano (1916, IX.4.3-23) estabelece a distinção entre discurso e
texto, ao considerar que este é o tecido linguístico daquele. Em seu estudo sobre oratória, considera que, na composição, as palavras, após serem escolhidas, devem ser organizadas de forma orgânica e arranjadas em um delicado tecido (textus, textum), ou seja, em uma trama, em uma urdidura, como uma ação de tecer (texere) o discurso, fixando-o pela escrita, em uma tessitura multimodal, plurissemiótica e plurissemântica.

A tessitura multimodal se irradia em formações plurissemióticas, constituídas por semioses, que são unidades de interpretação decorrentes não só da manifestação linguística, mas também de sistemas gráficos, tipográficos, ilustrativos, diagramadores. Da percepção semântica decorrem unidades de significado com diferentes graus de complexidade: fonológico, ortográfico, morfológico e sintático. As formações plurissemiótica e plurissemântica articulam o texto como uma unidade de significação multimodal instituída por múltiplas formas de linguagem que manifestam multiformes efeitos de sentido.

A articulação multimodal fixa uma discursivização de natureza retórica, arte do bem dizer em busca de um enredamento sedutor, que compreende todas as virtudes do discurso e ao mesmo tempo as qualidades do orador

1 Professor doutor, titular do Programa de Estudos Pós-Graduados em Língua Portuguesa da PUC-SP, Coordenador do curso de Letras: Língua Portuguesa da PUC-SP. 
(CÍCERO, 1995). A ação argumentativa, na tentativa de criar recursos persuasivos, deriva do caráter do orador (ethos), da emoção que desperta no auditório (pathos) e da consistência dos argumentos (logos) (ARISTÓTELES, 2005), sejam verdadeiros ou apenas prováveis que, no jogo enunciativo da intencionalidade proposta e da aceitabilidade prevista, consolida-se na verossimilhança, pois, nesse lance, nada é absolutamente verdadeiro ou absolutamente falso, tudo goza de uma relativa condição de verdade ou de falsidade.

O discurso retórico é cuidadosamente planejado para levar um determinado auditório, universal, particular ou de especialistas, a adquirir empatia com as emoções expostas pelo orador e por suas premissas, estimulando-o a reforçar ou alterar a opinião, caso necessário, reconhecendo-lhe, assim, uma condição de verdade. O discurso elaborado decorre de uma discursivização, ação sócio histórica de significar um termo ou expressão por meio da dimensão política, econômica e cultural. As expressões linguísticas assumem uma função não-gramatical e passam a cumprir uma função pragmática (MARTELOTTA et al, 1996).

Por a discursivização ser o processamento do discurso por unidades linguísticas, concebem-se variações semânticas por efeito dos contextos interacionais que se configuram em dois campos bem distintos, o campo das relações textuais, por meio dos articuladores de recorrência e de sequenciação, e o campo das relações entre o discurso e os indivíduos, por meio da interação entre interlocutores. Essa divisão possibilita que se distinga entre os operadores argumentativos, no nível textual; o processo de argumentação, no nível discursivo; e a argumentatividade, no nível cognitivo.

\section{Constituição teórica}

A distinção entre texto e discurso estabelecida por Quintiliano pode ser ampliada, primeiramente, pelas considerações teórico-práticas desenvolvidas por Bakhtin (2003 [1979]), sobre gênero de discurso e enunciado concreto; por Perelman e Olbrechts-Tyteca (1996 [1958]), sobre a revisão elaborada à retórica aristotélica quanto às ocorrências argumentativas; e por Carolyn Miller (1994 [1984]), sobre o redimensionamento da ação retórica na concepção de uma sociorretórica.

Com relação à definição de gênero, Bakhtin (2003) registra que cada enunciado particular é individual, mas cada campo de utilização da língua 
elabora seus tipos relativamente estáveis de enunciados, os quais denominamos gêneros do discurso. Quanto à noção de enunciado, observa que a utilização da língua se efetua em forma de enunciados (orais e escritos), concretos e únicos, que emanam dos integrantes duma ou doutra esfera da atividade humana.

Para Bakhtin (2003), "cada esfera dessa atividade comporta um repertório de gêneros do discurso que vai diferenciando-se e ampliando-se à medida que a própria esfera se desenvolve e fica mais complexa" (BAKHTIN, 2003, p. 262-280). Assim, o autor faz uma distinção entre gêneros de discurso primário (simples), próprios da comunicação espontânea do cotidiano, e gêneros de discurso secundário (complexo), característicos do uso formal das instituições.

Por essa perspectiva, todas as atividades discursivas se manifestam em gêneros que são a verdadeira forma de vida interacional em sociedade, por organizarem as esferas de atividades humanas e delas decorrerem. Destarte, a língua não é apenas um sistema de comunicação nem um simples sistema simbólico para expressar ideias, mas, muito mais, uma forma de ação (WITTGENSTEIN, 2009). É estabelecida, portanto, uma distinção entre expressão linguística e enunciado, importando para a análise de discurso muito mais este e menos aquela, que servirá de base para as perscrutações das peculiaridades organizacionais dos argumentos.

As mais variadas formas de expressão linguística são organizadas em enunciados que são, de fato, unidades reais da comunicação verbal, realizadas em condições próprias, que possibilitem o cumprimento do certame interacional intencionalidade/aceitabilidade. Nessa visão, as expressões linguísticas, em si, se encontram em um estado de incompletude ou inacabamento, pois só ganham sentido na relação com os enunciados já proferidos ou na projeção dos que ainda serão realizados, isto é, estão em função das formas de enunciações, realizadas nos momentos de interação. Para que sejam compreendidos os efeitos de sentido produzidos no processo de enunciação, é preciso que se considerem suas condições de produção, isto é, em que condições se deu sua ocorrência.

Essa acepção, dada ao vocábulo enunciado, faz alusão ao ato concreto de uso da linguagem, que aponta para a enunciação como sendo de natureza sócio histórica e constitutivamente ligada a enunciações anteriores e a enunciações posteriores, produzindo elos por onde circulam os discursos. No enunciado concreto, não está presente apenas a formulação individual das expressões linguísticas, mas também e, principalmente, a função interacional dos gêneros de discurso, circunscrita ao contexto e delineada pelo enunciado de outrem. 
O enunciado concreto, composto por uma interface linguística-textual-social, é endereçado a alguém e tem um propósito de incitá-lo. De acordo com Aristóteles (2005), a retórica é a arte de descobrir, em cada caso particular (por intermédio de enunciados concretos), os meios adequados de incitação, em que se empregam discursos persuasivos, para expor uma ideia, defender uma tese ou contrapor um argumento.

Os estudos aristotélicos são revisitados e revitalizados por Perelman e Olbrechts-Tyteca (1996). A nova retórica veio como um movimento associado à melhoria do ensino da composição argumentativa, por meio de postulados que indicam a necessidade de se adaptarem as estratégias discursivas para o exercício da persuasão. $O$ destaque é dado, principalmente, na preocupação de condicionar o discurso de acordo com o auditório, focalizando não só as artimanhas da língua, mas também as relações do artefato linguístico com domínios extralinguísticos, como os valores sócio históricos: político, econômico e cultural; que envolvem conviç̧ões, necessidades e crenças da audiência.

O processo argumentativo de persuasão, a partir da convergência entre linguístico e extralinguístico, traz à tona a noção de contexto social, consubstanciado pela ideia de objetivo ou propósito comunicativo, por se pensar a persuasão baseada na adaptação à ocorrência sócio histórica do discurso. Essas considerações de Perelman e Olbrechts-Tyteca (1996) se expandiram nos estudos sociorretóricos, pela ampliação do campo de visão do orador, ao tirar o foco exclusivamente do texto e passar a observar também o extratextual, tecendo estratégias discursivas entremeadas pelo social.

As noções preliminares da sociorretórica foram desenvolvidas por Miller (1994), ao considerar, primeiramente, gênero de discurso como uma ação social, pois o que se depreende do estudo de gênero de discurso não é apenas um padrão de formas e métodos para se atingir objetivos, mas também e sobretudo, quais objetivos podem-se ter para conseguir participar das ações de uma comunidade. Mas, para que a ação social se efetive, o gênero precisa ser socialmente identificado, o que só é possível pela repetição (recorrência) e pela similaridade (forma e substância) da produção de textos que dão ao gênero uma configuração social.

Aprender, entender e compreender as situações enunciativas encontradas determinam as possibilidades de fracasso ou sucesso da ação social circunscrita pelo gênero de discurso, uma vez que ele abarca aspectos dos padrões de convicções, necessidades e crenças do auditório a que se destina. O gênero como forma de ação social, torna-se dependente da estrutura e da complexidade de cada sociedade, envolvido em dois aspectos relevantes: 
a noção de situação retórica recorrente, entendida como tipificação, e a fusão entre forma, substância e situação.

Gênero de discurso, como uma ação retórica tipificada, ganha uma configuração sócio-discursiva, assim explicitada por Miller (1994):

É por meio do processo de tipificação que criamos recorrência,
analogias, similaridades. O que recorre não é uma situação material
(um evento real, objetivo, verdadeiro), mas nosso construto de um
tipo. A situação tipificada, incluindo tipificações de participantes,
sustenta a tipificação em retórica. A comunicação bem-sucedida
requer que os participantes compartilhem tipos comuns; isso é
possível na medida em que os tipos são socialmente criados (ou
biologicamente inatos). (MILLER, 1994, p. 157).

Os gêneros de discurso são ações retóricas tipificadas que, necessariamente, implicam situação e motivação, uma vez que a ação humana é sobremaneira motivada e só a partir dessa motivação as ações podem ser interpretadas. Dessa forma, além dos critérios clássicos, já consagrados, para análise do gênero de discurso, conteúdo temático, construção composicional e estilo, para a referida autora, é essencial incluir a noção de motivação, pela intenção e pelo efeito, e a de situação retórica, pelo contexto e pelas demandas situacionais.

A motivação, no caso, não é individual, mas decorrente de um propósito ou de uma necessidade sociais convencionados pela recorrência de produção textual, consolidada como uma ação retórica tipificada, reproduzida incessantemente, tornando-se um propósito social, presente no gênero, em que as ações particulares se inter-relacionam com as sociais. As relações e os sistemas sociais são produzidos, reproduzidos e estruturados em interações sociais ao longo do espaço e do tempo; e as estruturas são constituídas por regras que concretizam a manutenção e a consolidação dos sistemas a partir da recorrência quase que natural delas.

Miller (1994) considera que o gênero pertence ao comunitário e não ao individual e que tem a função de estabelecer a mediação entre eles, entre o público e o privado, sendo o elo estruturador que liga, a meio caminho, a mente individual à grupal. $\mathrm{O}$ gênero tem o caráter estruturado por essa mediação, da qual aflora o conceito de comunidade retórica, que busca suprir os propósitos e as necessidades em uma perspectiva sociorretórica. Comunidade retórica não se refere a uma condição geográfica ou temporal, mas à constituição interacional discursiva, ou seja, representada e desenvolvida por meio do discurso, entendido como a linguagem investida de uma prática social. 
É por meio da convencionalização, dada pela recorrência e pela situação interacional, que as práticas retóricas se transformam em ações sociais, construídas e mantidas socialmente, o que também explica a dinamicidade do gênero, que pode evoluir, involuir, emergir. Conforme a convenção comunitária se altera, os gêneros também vão se modificando, podendo alguns se extinguirem e outros surgirem, na dependência das necessidades, das relações e da complexidade de comunicação e ações sociais.

Para identificação de gêneros de discurso, Miller (1994) os considera, primeiramente, como categorias convencionalizadas de discurso que se baseiam em ações retóricas tipificadas e que adquirem significado no contexto, na situação em que estão envolvidos; em segundo lugar, como passíveis de interpretação por intermédio das regras que os moderam; em terceiro, como sendo diferenciados pela associação entre substância e forma; em quarto, como constitutivos da vida cultural, pela recorrência; e, por último, como mediadores entre as intenções, as exigências e as motivações que intermediam o particular e o social, o privado e o público, a idiossincrasia e o recorrente.

As noções de propósito e contexto trouxeram contribuições significativas para o aprofundamento do estudo dos gêneros de discurso, pois passa-se a divisar a produção textual como uma instância cujo objetivo é atingir determinado propósito em certa situação social, em vez de se prestar atenção exclusiva ao texto ele mesmo, como artefato linguístico apenas. Por essa complementação conceitual, o discurso ganha força como forma de ação social, e os gêneros que o conformam, como artefatos culturais que se configuram em ações retóricas recorrentes, atualizadas nos movimentos argumentativos que se entrelaçam na tessitura textual.

\section{Exemplificação prática}

As ações sociais, impreterivelmente, para serem realizadas, envolvem linguagem. Toda linguagem é conformada por uma prática social que se configura a partir do arcabouço de conhecimentos prévios, individuais e comunitários, armazenados pelo sujeito. O sujeito, por desempenhar um papel social, transforma seus conhecimentos em discurso por meio de uma ação retórica que é o processo de discursivização moldado por uma intencionalidade argumentativa, identificada como argumentatividade.

$\mathrm{O}$ discurso produzido se configura sob a forma de gêneros tipificados, 
ou seja, recorrentes, socialmente contextualizados e argumentativamente motivados; é instaurado o processo de argumentação. O discurso é tecido linguisticamente pelo texto, instância em que os argumentos se explicitam e a ação retórica se consolida.

À guisa de ilustração, serão analisados dois textos, um descritivo e outro narrativo, tendo por critérios a configuração como gênero, a expansão textual por meio dos tipos de argumentos apresentados e a ação retórica motivadora.

Ser descritivo, narrativo ou dissertativo não implica classificação de gênero de discurso, mas sim, tipologia de texto, que não é socialmente institucionalizada, mas histórica e culturalmente constituída. $\mathrm{O}$ gênero discursivo, por ter sua configuração contextualizadamente estabelecida, necessita de uma recorrencialidade, para ser tipificado, e, por isso, goza de uma relativa estabilidade. A tipologia textual, por sua tradição histórico-cultural, mantém uma formação que independe da recorrência para ser identificada, pois está prototipicamente consolidada.

Estar em prosa ou em verso não é traço caracterizador de gênero, pois não é uma característica própria do discurso, mas sim da arquitetura do texto, de sua multimodalidade configurativa. O texto de Manuel Bandeira, que vem a seguir, está em um livro de poesias, mas apresenta um aspecto mais apropriado a uma prosa narrativa. E, dada a relatividade de identificação do gênero de discurso, pode ser classificado, até, como uma crônica, estilo também explorado pelo autor. Se assim o for, é uma crônica-ensaio, por seu atributo argumentativo, que revela uma visão abertamente crítica da realidade cultural e ideológica do Brasil; escrita em linguagem literária, no molde ficcional. O mesmo acontece com o texto de Carlos Drummond de Andrade, poeta também cronista, só que acrescido de um tom humorístico, irônico e sarcástico.

\section{tragédia brasileira ${ }^{2}$}

Misael, funcionário da Fazenda com 63 anos de idade;

Conheceu Maria Elvira na Lapa _ prostituída, com sífílis, dermite nos dedos, uma aliança empenhada e os dentes em petição de miséria.

Misael tirou Maria Elvira da vida, instalou-a num sobrado no Estácio, pagou médico, dentista, manicura... Dava tudo quanto ela queria. 
Quando Maria Elvira se apanhou de boca bonita, arranjou logo um namorado.

Misael não queria escândalo. Podia dar uma surra, um tiro, uma facada.

Não fez nada disso: mudou de casa.

Viveram três anos assim.

Toda vez que Maria Elvira arranjava namorado, Misael mudava de casa.

Os amantes moraram no Estácio, Rocha, Catete, Rua General Pedra, Olaria, Ramos, Bonsucesso, Vila Isabel, Rua Marquês de Sapucaí, Niterói, Encantado, Rua Clapp, outra vez no Estácio, Todos os Santos, Catumbi, Lavradio, Boca do Mato, Inválidos...

Por fim na rua da Constituição, onde Misael, privado de sentidos e de inteligência, matou-a com seis tiros, e a polícia foi encontrá-la caída em decúbito dorsal, vestida de organdi azul.

O texto traz um percurso narrativo, com a apresentação de uma situação inicial em que são identificadas as personagens e as características delas que são pertinentes para o desenrolar da trama: Misael, funcionário da Fazenda com situação financeira estável, e Maria Elvira, prostituta falida. O primeiro conflito é este, relacionado a ela, que será solucionado quando ele, nela, investir. O segundo conflito surge para ele, diante da volubilidade atitudinal dela, que o leva a um desfecho criminoso.

$\mathrm{O}$ crime praticado por Misael procede de uma série de acontecimentos decorrentes da conduta de Maria Elvira. Neste percurso, cada localidade em que eles moram caracteriza o tipo de amante que ela foi tendo e a sua degenerada degradação. O primeiro amante faz referência ao próprio fundador da cidade do Rio de Janeiro, ou seja, alguém de uma família tradicional; o segundo, um homem forte, firme, inabalável. Talvez, pelas características desses dois primeiros amantes é que fez Misael recuar e não tomar uma atitude mais severa e brusca: "Podia dar uma surra, um tiro, uma facada."

Isso se agrava e o acanha mais pelos perfis do terceiro e do quarto amantes, pois um é do Catete, bairro, na ocasião, em que se localizava o palácio, residência do presidente da República, e o outro, um general de linha dura, "Pedra". E a diversificação aumenta continuadamente, pelos operários, "Olaria" e "Lavradio"; pela referência ao eixo central de um tronco, ou seja, de um homem poderosamente potente, "Ramos"; pelas experiências sexuais excêntricas, "Isabel" e "Encantado"; pelo integrante da família real, "Marquês", pelos representantes da raça indígena, "Niterói" 
e "Catumbi"; pela naturalidade estrangeira, "Clapp"; pela reincidência, outra vez "Estácio"; pelos representantes do clero, "Todos os Santos"; pela localização, independente da pessoa, na "Boca do Mato"; por fim, pelos indivíduos enfermos, incapazes, mutilados, "Inválidos"; etc., “...”.

São argumentos baseados na estrutura do real, elaborados a partir de uma realidade construída para estabelecer juízos de valor admitidos ou para os quais se busca admissão. Por essa natureza, é um tipo de argumentação que não se apoia na lógica, mas na experiência com função explicativa das ocorrências. Tem-se, assim, argumentos de direção, que consistem em procedimentos críticos de atos ou acontecimentos, com base no perigo das tendências que os orientam, no caso, a volubilidade desenfreada e irresponsável de Maria Elvira; e argumentos de pessoas e atos que compreende avaliar alguém pela articulação entre seu caráter revelado por seus atos, no caso, a irresponsabilidade inconsequente e ingrata da personagem em questão.

Convém que a atitude de Misael também seja analisada, pois ele cometeu o crime na "rua da Constituição", símbolo dos direitos e deveres dos cidadãos, garantidos pela lei fundamental e suprema da nação. Misael e Maria Elvira tinham seus deveres, ele de prover e ela de respeitar e resguardar-se. Misael empenhou-se, "Misael não queria escândalo. Podia dar uma surra, um tiro, uma facada. / Não fez nada disso: mudou de casa. / Viveram três anos assim. / Toda vez que Maria Elvira arranjava namorado, Misael mudava de casa.." Maria Elvira desvirtuou, "Quando Maria Elvira se apanhou de boca bonita, arranjou logo um namorado.[...] Os amantes moraram..."; o que deu o direito a Misael de defender a honra, restabelecer a ética, termo originário do grego ethos, que significa modo de ser, costume ou hábito e que reflete o caráter e a natureza de cada indivíduo, e, dessa forma, resgatar sua integridade.

\section{Cidadezinha qualquer ${ }^{3}$}

Casas entre bananeiras

Mulheres entre laranjeiras

Pomar amor cantar. 
Um homem vai devagar.

Um cachorro vai devagar.

Um burro vai devagar.

Devagar... as janelas olham.

Eta vida besta, meu Deus.

O texto é construído por meio de sinédoques que apresentam partes selecionadas de uma cidade e que por ela passam a valer como um todo. As partes selecionadas são: casas, bananeiras, mulheres, laranjeiras, pomar, homem, cachorro, burro e janelas. O conhecimento prévio de cidade não se restringe apenas a esses elementos, mas a muitos outros. Mas esses foram os escolhidos para caracterizar a cidadezinha em questão que não é identificada uma especificidade, uma vez que é "qualquer".

A sinédoque é um recurso próprio da construção de uma expressão metafórica, portanto, pela triagem feita, "cidadezinha" tem um valor metafórico. Metáfora, aqui, precisa ser entendida na extensão conceitual dada por Lakoff e Johnson (2002), de que o nosso sistema conceptual é fundamentalmente metafórico, pois as metáforas não se encontram na linguagem, mas sim no pensamento inconsciente, infiltradas na vida cotidiana, tanto na linguagem, quanto no pensamento e na ação. O papel da linguagem é apenas o de explicitar essas metáforas conceptuais por meio de "expressões metafóricas".

Se na expressão metafórica está implicada uma ação de linguagem, conceptualmente constituída pela vida cotidiana, tem-se aí uma configuração sociorretórica de um propósito intermediador do individual com o comunitário e isso, por meio da configuração argumentativa presente no texto. Assim, a configuração sinedótica não é outra coisa senão uma eleição de argumentos que conduzem e dão sustentação à conclusão avaliativa apresentada: "Eta vida besta, meu Deus!"

Vida besta por ser de uma cidadezinha, diminutivo desprestigioso, que tem mulheres e um só homem, estúpido, obtuso, não só por se assemelhar instintivamente a um cachorro e a um burro, no fazer, mas também por ser a junção dos dois e, assim, se identificar com uma besta, animal estéril, que não se reproduz por ser híbrido, fruto do cruzamento de duas espécies diferentes, de jumento com égua ou de cavalo com jumenta.

O texto é organizado por uma tipologia descritiva que apresenta, inicialmente, um referente, de forma genérica, "cidadezinha qualquer", que, em seguida, é exibido por traços, selecionadamente convenientes, 
"casas, bananeiras, mulheres, laranjeiras, pomar, homem, cachorro, burro, janela”, para atribuir-lhe características, "vai devagar e devagar ... olham", que propiciarão uma avaliação final, "vida besta", do todo por meio das partes, pois cada parte equivale ao todo, é uma "cidadezinha qualquer" porque "vai devagar" e bisbilhota a vida alheia - "janelas olham”. O recurso sinedótico articula uma expressão metafórica e revela o movimento argumentativo pautado.

Quanto à manifestação argumentativa presente no texto, pode-se considerar, dos argumentos quase lógicos, a contradição como recurso de ironia, na relação entre "mulheres" e 'um (só) homem”, estéril, estúpido e obtuso, por ser irracionalmente animalizado, pela analogia estabelecida entre ele, o cachorro, o burro e a besta, o que traz uma miscigenação com a argumentação fundada na estrutura do real. Há, também, do recurso quase lógico, a reciprocidade, que trata da mesma forma situações que são contrapartes uma da outra, criando uma sensação de simetria que incide sobre o que é comum e que coloca em segundo plano o que as diferencias, "um homem vai devagar", "um cachorro vai devagar", "um burro vai devagar”, "devagar... as janelas olham”. Outros argumentos existem, mas, por ora, ficarão esses, a título de exemplificação.

Nos dois textos analisados, a ação retórica motivadora é fruto de normas e de convenções determinadas pelas práticas sociais, pelas formas de interação e pelas recorrências de produção da postura crítico-avaliativa caracterizadora do gênero crônica-ensaio. Esse gênero representa a posição enunciativa do orador por meio da movimentação argumentativa que articula vários tipos de argumento, baseados tanto na estrutura do real quanto em fundamentos quase lógicos.

\section{Considerações finais}

Os gêneros atualizam uma ação social, por meio da articulação de uma dinâmica retórica de argumentos, decorrente de uma motivação que representa a realização individual de uma tipificação comunitária em que o agir retórico se adapta socialmente, pelo gênero eleito, aos vários contextos e circunstâncias da vida. O sujeito do discurso avança em seus interesses, molda suas significações no interior de complexos sistemas sociais, atribui valores e avalia consequências de interações verbais ao utilizar, adequadamente, diferentes gêneros.

A linguagem, como produto de uma evolução sócio histórica, vale-se de técnicas de emprego de vocábulos e de expressões sintáticas, a fim de 
consolidar interações pela qualidade dos argumentos selecionados e organizados mediante um raciocínio lógico e coerente. Assim se configura o gênero circunscrito por requisitos fundamentais para que se compreenda o funcionamento social do discurso, atualizado por sequências tipológicas textuais e ajustado aos modos de comunicação do grupo ao qual o sujeito se vincula ou aspira se conectar, permitido pelo comportamento sociorretórico da comunidade discursiva que é o fator determinante para a comunicação. 


\section{Referências}

ARISTÓTELES. Retórica. Trad. e notas Manuel Alexandre Júnior, Paulo Farmhouse e Abel do Nascimento Pena. Lisboa: Imprensa Nacional - Casa da Moeda, 2005.

BAKHTIN, M. Estética da criação verbal. São Paulo: Martins Fontes, 2003.

BANDEIRA, M. Estrela da vida inteira. 36 ed. Rio de Janeiro: Nova Fronteira, 1993.

CÍCERO. Acerca del Orador. Intro., versão e notas Amparo Gaos Schmidt. 2 volume. Ciudad del México: UNAM, 1995.

DRUMMOND de ANDRADE, C. Alguma poesia. São Paulo: Companhia das Letras, 2013.

LAKOFF, G.; JOHNSON, M. Metáforas da vida cotidiana. Coordenação de trad.: Mara Sophia Zanotto. São Paulo: Mercado das Letras, 2002.

MARTELOTTA, M. E. T. et al. (orgs.) Gramaticalização no português do Brasil: uma abordagem funcional. Rio de Janeiro: Tempo Brasileiro, 1996.

MILLER, C. Genre as social action. In: FREEDMAN, A.; MEDWAY, P. (Org.). Genre and the new rhetoric. London: Taylor \& Francis 1994. p. 23-42. (Originalmente publicado em: Quarterly Journal of Speech, v. 70, p. 151-167, 1984)

, C. Estudos sobre gênero textual, agência e tecnologia. In: DIONÍSIO, A.; HOFFNAGEL, J. (Org.). Estudos sobre Gênero Textual, Agência e Tecnologia de Carolyn R. Miller. Recife: Universitária da UFPE, 2009.

C. Gênero textual, agência e tecnologia. São Paulo: Parábola/Recife:

Ed. Universitária da UFPE, 2012.

PERELMAN, C.; OLBRECHTS-TYTECA, L. Tratado da argumentação: a nova retórica. São Paulo: Martins Fontes, 1996.

QUINTILIANO, M. Instituiciones oratorias. Trad. Ignacio Sandier. Madrid: Perlado Paes e Cia, 1916.

WITTGENSTEIN, L. Investigações Filosóficas. Trad. Marcos G. Montagnoli. 6 ed. Petrópolis: Vozes, 2009. 
